\title{
Glossitis and esophagitis from herpes simplex virus type 1 infection
}

\author{
Narumi Asano MD, Yasuhiro Kano MD, Chika Takarada MD
}

- Cite as: CMAJ 2021 December 20;193:E1921. doi: 10.1503/cmaj.210352

A n 81-year-old woman presented to the emergency department with a 2-week history of malaise, fever and anorexia, with oral pain and odynophagia. Her medical history was remarkable only for type 2 diabetes mellitus. She was not taking any immunosuppressive agents. Her body temperature was $37.7^{\circ} \mathrm{C}$, and other vital signs were normal. Physical examination showed multiple yellowish-white, pseudomembranous lesions on the patient's tongue (Figure 1A). The rest of the physical examination was unremarkable. Esophagogastroduodenoscopy showed multiple shallow ulcers with a white coating (Figure 1B and Appendix 1, available at www.cmaj.ca/lookup/doi/10.1503/ cmaj.210352/tab-related-content). Glossal and esophageal biopsies showed multinucleated cells with moulded, groundglass nuclei (Appendix 2, available at www.cmaj.ca/lookup/ doi/10.1503/cmaj.210352/tab-related-content). Results from polymerase chain reaction and immunohistochemical staining of the specimens were positive for herpes simplex virus type 1 (HSV-1), and we diagnosed herpetic glossitis and esophagitis. We did not find any evidence of malignant disease on a whole body computed tomography scan and upper and lower endoscopy. The patient's HIV test result was negative and her hemoglobin $A_{1 c}$ was $7.2 \%$. We treated her with a 7-day course of acyclovir, intravenously because of her odynophagia, and the oral and esophageal lesions completely resolved.

Herpes labialis is the most common manifestation of HSV-1 infection, accounting for about $90 \%$ of reactivated infections. ${ }^{1}$ In contrast, herpetic glossitis and esophagitis are uncommon manifestations of HSV-1 infection. The macroscopic findings of herpetic glossitis are diverse, including single or multiple vesicles, ulcers, linear or crosshatched fissures and pseudotumoral plaques, as with our patient. ${ }^{2}$ The differential diagnosis includes oral candidiasis, syphilis, tuberculosis, pemphigus, lichen planus and hairy leukoplakia. ${ }^{3}$ Herpetic glossitis can coexist with herpetic esophagitis, and esophagogastroscopy should be considered if the patient has odynophagia. Herpetic esophagitis characteristically manifests as well-circumscribed ulcers that are sometimes described as having a volcano-like appearance (Appendix 1). ${ }^{4}$

Diagnosis of herpetic glossitis and esophagitis can be made clinically if the presentation is typical; otherwise, virological confirmation is necessary to differentiate the disease from other entities. ${ }^{1}$ Treatment consists mainly of antiviral agents, including acyclovir, valacyclovir and famciclovir, after considering the patient's immune status and disease severity.

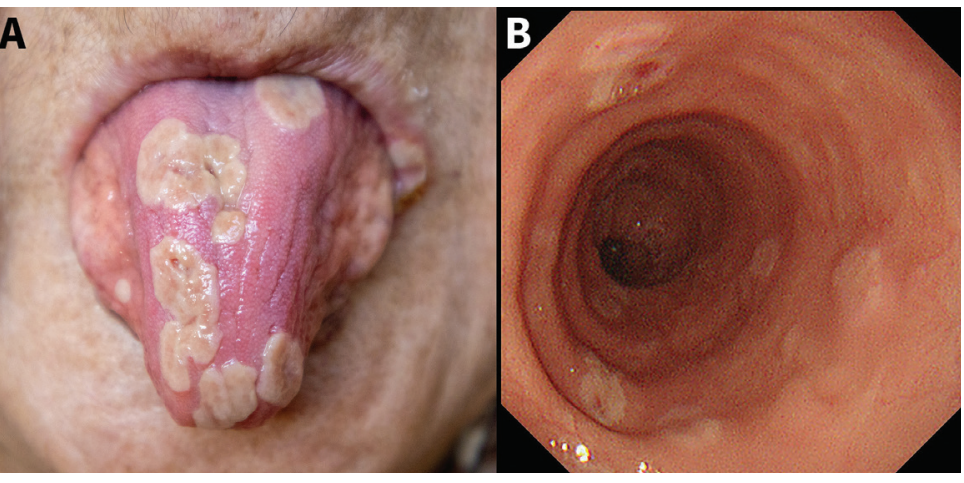

igure 1: Photographs of an 81-year-old woman with (A) herpetic glossitis, ppearing as pseudotumoral plaques, and (B) herpetic esophagitis, appearing as discrete, diffusely scattered, shallow ulcers on endoscopy.

\section{References}

1. Usatine RP, Tinitigan R. Nongenital herpes simplex virus. Am Fam Physician 2010;82:1075-82.

2. Schwob E, Dandurand M, Stoebner PE. Herpetic glossitis. Eur J Dermato/ 2020;30:61-2.

3. Hirota TK, Young RJ III, Warschaw KE. A 64-year-old man with glossitis. Arch Dermatol 2001;137:85-90.

4. Takeuchi Y, Tagashira Y, Kawai S, et al. Volcano-like shallow oesophageal ulcers in a patient with a history of cord-blood transplantation. Lancet Infect Dis 2016;16:384.

\section{Competing interests: None declared.}

This article has been peer reviewed.

The authors have obtained patient consent.

Affiliations: Department of Internal Medicine (Asano, Kano, Takarada), National Hospital Organization Tochigi Medical Center, Tochigi, Japan; Department of General Internal Medicine (Kano), Tokyo Metropolitan Tama Medical Center, Tokyo, Japan

Content licence: This is an Open Access article distributed in accordance with the terms of the Creative Commons Attribution (CC BY-NCND 4.0) licence, which permits use, distribution and reproduction in any medium, provided that the original publication is properly cited, the use is noncommercial (i.e., research or educational use), and no modifications or adaptations are made. See: https://creativecommons.org/ licenses/by-nc-nd/4.0/

Acknowledgements: The authors thank Dr. Masafumi Nishikawa (Department of Pathology, National Hospital Organization, Tochigi Medical Center) for his thoughtful comments on the pathologic findings. They are also grateful to Mr. James R. Valera for his assistance in editing the manuscript.

Correspondence to: Yasuhiro Kano, yasuhiro.kano.21@gmail.com 